\title{
Biofilm formation by clinical isolates and the implications in chronic infections
}

\author{
Carlos J Sanchez Jr ${ }^{1 *}$, Katrin Mende ${ }^{2,3}$, Miriam L Beckius ${ }^{4}$, Kevin S Akers ${ }^{1,3}$, Desiree R Romano ${ }^{1}$, \\ Joseph C Wenke ${ }^{1}$ and Clinton K Murray ${ }^{3}$
}

\begin{abstract}
Background: Biofilm formation is a major virulence factor contributing to the chronicity of infections. To date few studies have evaluated biofilm formation in infecting isolates of patients including both Gram-positive and Gram-negative multidrug-resistant (MDR) species in the context of numerous types of infectious syndromes. Herein, we investigated the biofilm forming capacity in a large collection of single patient infecting isolates and compared the relationship between biofilm formation to various strain characteristics.

Methods: The biofilm-forming capacity of 205 randomly sampled clinical isolates from patients, collected from various anatomical sites, admitted for treatment at Brooke Army Medical Center (BAMC) from 2004-2011, including methicillin-resistant/methicillin susceptible Staphylococcus aureus (MRSA/MSSA) ( $n=23)$, Acinetobacter baumannii $(\mathrm{n}=53)$, Pseudomonas aeruginosa $(n=36)$, Klebsiella pneumoniae $(n=54)$, and Escherichia coli $(n=39)$, were evaluated for biofilm formation using the high-throughput microtiter plate assay and scanning electron microscopy (SEM). Relationships between biofilm formation to clonal type, site of isolate collection, and MDR phenotype were evaluated. Furthermore, in patients with relapsing infections, serial strains were assessed for their ability to form biofilms in vitro.
\end{abstract}

Results: Of the 205 clinical isolates tested, 126 strains (61.4\%) were observed to form biofilms in vitro at levels greater than or equal to the Staphylococcus epidermidis, positive biofilm producing strain, with $P$. aeruginosa and $S$. aureus having the greatest number of biofilm producing strains. Biofilm formation was significantly associated with specific clonal types, the site of isolate collection, and strains positive for biofilm formation were more frequently observed to be MDR. In patients with relapsing infections, the majority of serial isolates recovered from these individuals were observed to be strong biofilm producers in vitro.

Conclusions: This study is the first to evaluate biofilm formation in a large collection of infecting clinical isolates representing diverse types of infections. Our results demonstrate: (1) biofilm formation is a heterogeneous property amongst clinical strains which is associated with certain clonal types, (2) biofilm forming strains are more frequently isolated from non-fluid tissues, in particular bone and soft tissues, (3) MDR pathogens are more often biofilm formers, and (4) strains from patients with persistent infections are positive for biofilm formation.

Keywords: Biofilm formation, Clinical isolates, Chronic infection, Multidrug-resistant, MRSA

\footnotetext{
* Correspondence: carlos.j.sanchez3@us.army.mil

${ }^{1}$ Department of Extremity Trauma and Regenerative Medicine, United States Army Institute of Surgical Research, Ft. Sam Houston, San Antonio, TX, USA Full list of author information is available at the end of the article
}

\section{Biomed Central}

(C) 2013 Sanchez et al.; licensee BioMed Central Ltd. This is an Open Access article distributed under the terms of the Creative Commons Attribution License (http://creativecommons.org/licenses/by/2.0), which permits unrestricted use, distribution, and reproduction in any medium, provided the original work is properly cited. 


\section{Background}

Multidrug-resistant (MDR) organisms, including Acinetobacter baumannii, methicillin-resistant Staphylococcus aureus (MRSA), and extended spectrum beta-lactamase (ESBL) producing Gram-negative bacteria, are frequently implicated as the causative agents of acute and chronic infections contributing significantly to patient morbidity and mortality, as well as increased health care costs associated with treatment $[1,2]$. Numerous studies to date indicate that human infections are, in large part, caused by the ability of bacteria to develop surface attached polymicrobial communities known as biofilms [3-5]. Microbial biofilms consist of groups of bacterial cells adherent to a surface and enclosed within a self produced extracellular matrix [6]. Adaptation to surface attached growth within a biofilm is accompanied by significant changes in gene and protein expression, as well as metabolic activity $[7,8]$ which confers resistance to antimicrobial therapy $[9,10]$ and host mechanisms of clearance $[11,12]$. Many pathogenic and nosocomial bacteria have been observed to predominantly exist as biofilms, in both natural environments and within infected tissues as polymicrobial communities [4,5,13-15]. Importantly, biofilm formation is implicated as a significant factor involved in a number of chronic human infections [4,16,17].

Although there are numerous studies to date describing the ability of clinical strains to form biofilms in vitro (Additional file 1), these have varied widely in their study design, method of characterizing isolates and their biofilms, strains and number of isolates used, and most have omitted molecular assessments of strain relatedness to ensure a genetically heterogeneous sample and link biofilm production to strain type, with the exception of few studies evaluating biofilm formation and SCCmec and spa typing in staphylococci [18-22]. Likewise, few studies have surveyed biofilm formation among Gram-negative clinical isolates outside the context of genitourinary tract infections [23,24]. Furthermore, to our knowledge although biofilms have been implicated to be involved in chronic infections, no studies have characterized biofilm production from isolates recovered from relapsed infections where the clonal identity was proven identical to the initial infecting strains. Herein, we evaluated the biofilm forming capacity in a large collection of single-patient bacterial isolates, representing both Gram-positive and Gram-negative bacterial species, recovered from patients admitted for

Table 1 Characteristics of clinical isolates used in this study

\begin{tabular}{|c|c|c|c|c|c|}
\hline Bacterial species & Clinical isolates & \# of patients & Pulsed- Field Type (PFTs) & *Phenotype & Site of isolation \\
\hline \multirow[t]{6}{*}{ E. coli } & 39 & 32 & $1(n=4)$ & $E S B L+(n=31)$ & Wound culture $(n=10)$ \\
\hline & & & $2(n=5)$ & & Blood $(n=4)$ \\
\hline & & & $3(n=3)$ & & Urine $(n=21)$ \\
\hline & & & $4(n=7)$ & & \\
\hline & & & $7(n=5)$ & & \\
\hline & & & Other $(n=15)$ & & \\
\hline \multirow[t]{4}{*}{ K. pneumoniae } & 54 & 33 & $1(n=6)$ & $\operatorname{MDR}(n=54)$ & Wound culture $(n=39)$ \\
\hline & & & $2(n=8)$ & & Blood $(n=10)$ \\
\hline & & & $3,4,14,16,17,18(n=5)$ & & Respiratory $(n=5)$ \\
\hline & & & Other $(n=10)$ & & \\
\hline \multirow[t]{3}{*}{ P. aeruginosa } & 36 & 17 & $1(n=7)$ & $\operatorname{MDR}(n=28)$ & Wound culture $(n=29)$ \\
\hline & & & $2,18(n=5)$ & & Blood $(n=7)$ \\
\hline & & & Other $(n=19)$ & & \\
\hline \multirow[t]{4}{*}{ A. baumannii } & 53 & 47 & $1(n=13)$ & $\operatorname{MDR}(n=46)$ & Wound culture $(n=31)$ \\
\hline & & & $5(n=4)$ & & Blood $(n=20)$ \\
\hline & & & $2,3,4,6,7,14(n=5)$ & & Urine $(n=1)$ \\
\hline & & & Other $(n=6)$ & & Respiratory $(n=1)$ \\
\hline \multirow[t]{4}{*}{ S. aureus } & 23 & 21 & USA100 (n=10) & MRSA $(n=15)$ & Wound culture $(n=14)$ \\
\hline & & & USA200, USA800 $(n=4)$ & MSSA $(n=8)$ & Blood $(n=4)$ \\
\hline & & & USA300 ( $n=2)$ & & Respiratory ( $n=5$ ) \\
\hline & & & USA700 $(n=3)$ & & \\
\hline
\end{tabular}

*A multidrug-resistant (MDR) organism was defined as any extended spectrum beta-lactamase (ESBL)-producing bacteria, or if resistant to all tested antimicrobials in 3 or more classes of antimicrobial agents (penicillins/cephalosporins, carbapenems, aminoglycosides, and quinolones) not including tetracyclines or colistin. 


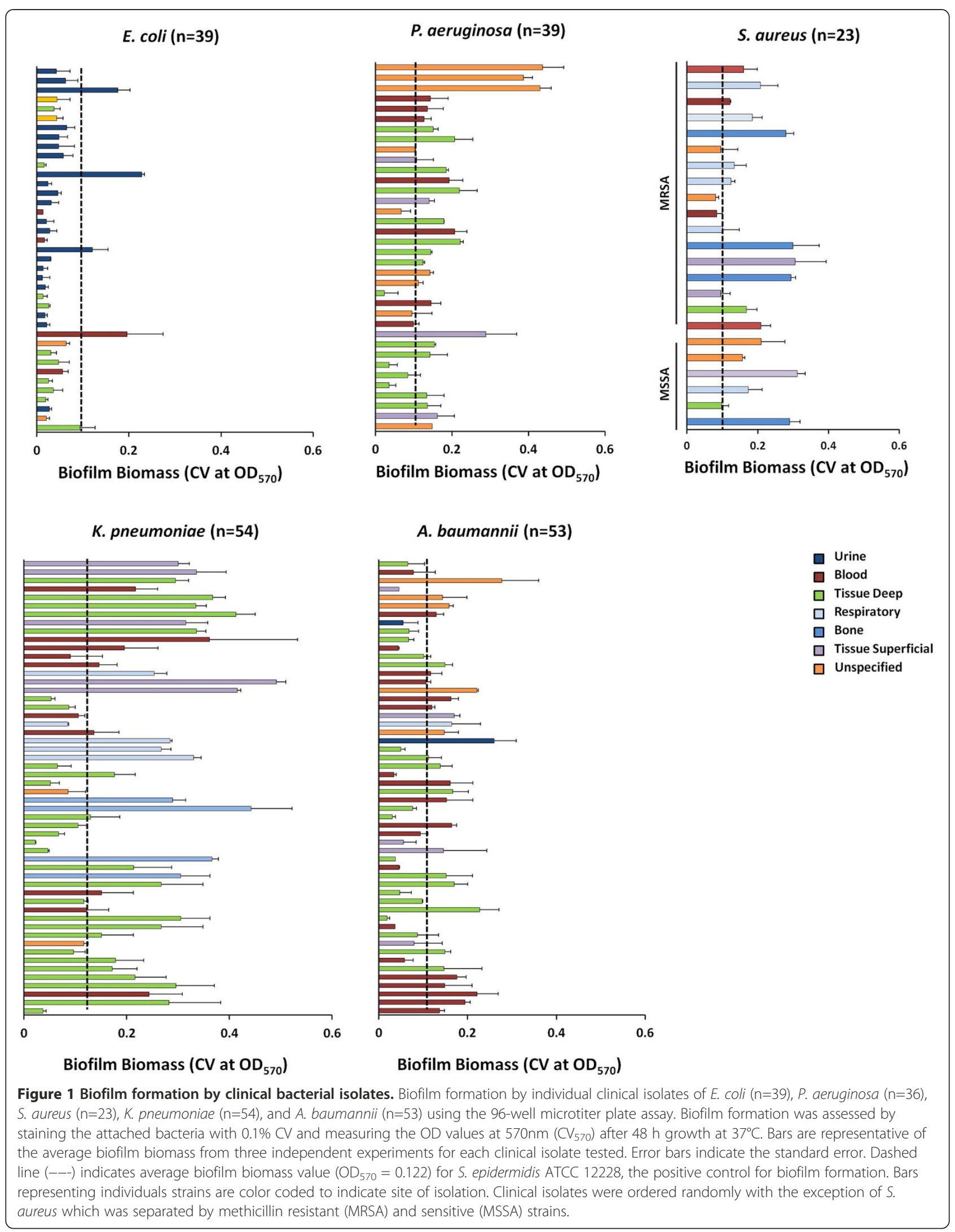



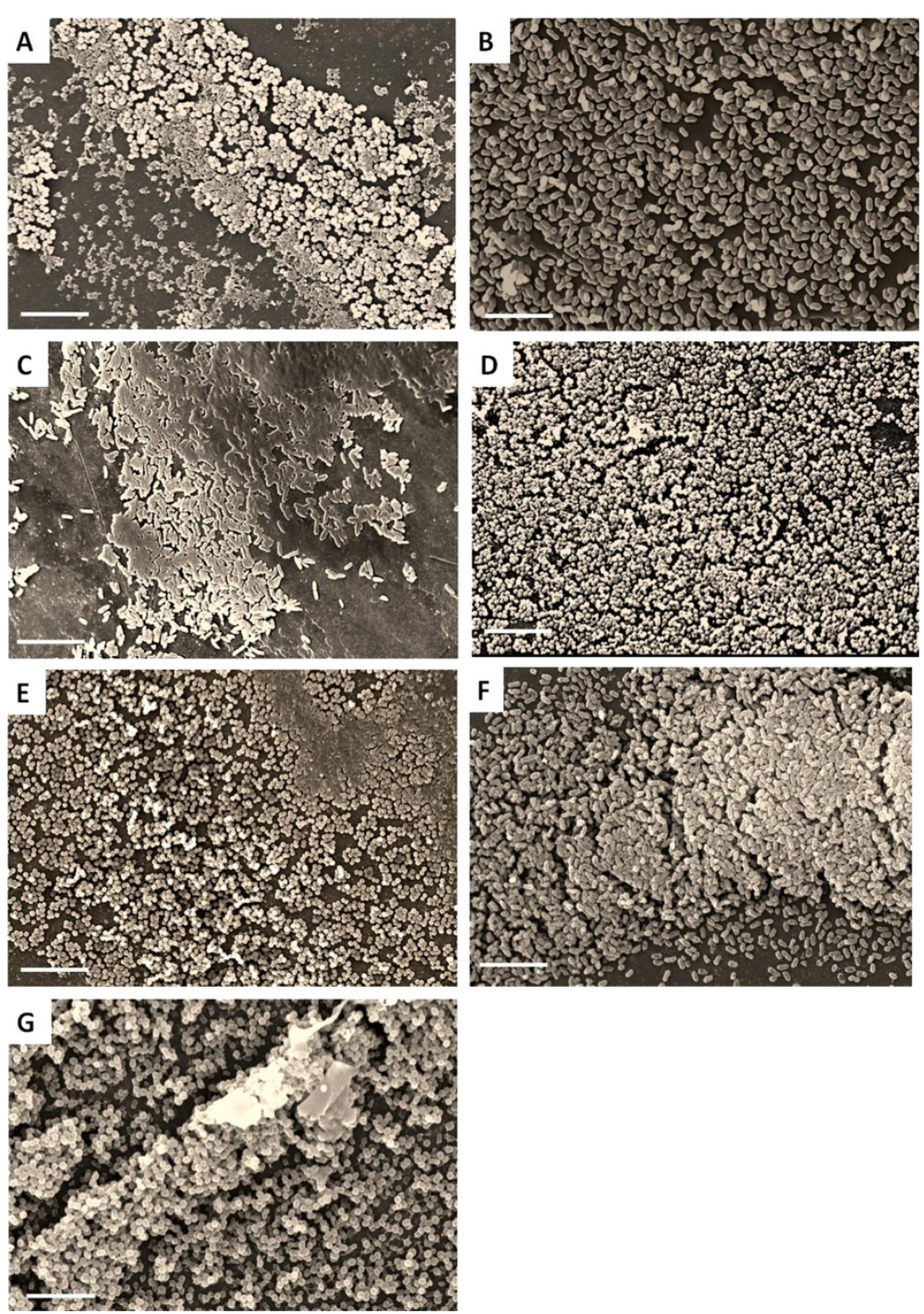

Figure 2 Scanning Electron Microscopy (SEM) images of biofilms. Representative SEM images of biofilms established on polystyrene pegs following $48 \mathrm{~h}$ incubation at $37^{\circ} \mathrm{C}$ from a selected biofilm producing strain of each bacterial species; including A) S. epidermidis ATCC 12228 (positive control), B) E. coli, C). P. aeruginosa, D) S. aureus (MRSA), E) S. aureus (MSSA), F) K. pneumoniae, and G) A. baumannii. SEM pictures were taken at 2000X magnification; inset white bar is representative of 10 microns.

treatment at our medical facility for numerous types of infectious syndromes. Additionally, the biofilm formation phenotype was evaluated in the context of relapsing infection, where serial isolates were available for study.

\section{Methods}

Bacterial isolates and growth conditions

The 205 clinical isolates used in this study were selected from a strain repository at Brooke Army Medical Center (BAMC; Fort Sam Houston, TX, USA). Bacterial strains from the repository were collected from patients as part of the standard care and infection control policy not related to research from 2004-2011. The 205 single and serial clinical isolates were randomly selected from the strain collection representing a total of 150 patients and multiple anatomical collection sites, including wound cultures, bone, respiratory tract, urine and blood (Table 1). As a positive control for biofilm formation, the previously characterized biofilm forming strain S. epidermidis ATCC strain 12228 was used $[25,26]$. Bacterial cultures were frozen and maintained at $-80^{\circ} \mathrm{C}$ and sub-cultured on blood agar plates (Remel, Lenexa, KS) overnight at $37^{\circ} \mathrm{C}$ prior to each experimental assay. With the exception of $S$. aureus, which was cultured in tryptic soy broth (TSB), all bacteria were grown in Luria-Bertani broth (LB) overnight at $37^{\circ} \mathrm{C}$. Antimicrobial susceptibility testing for all strains was 


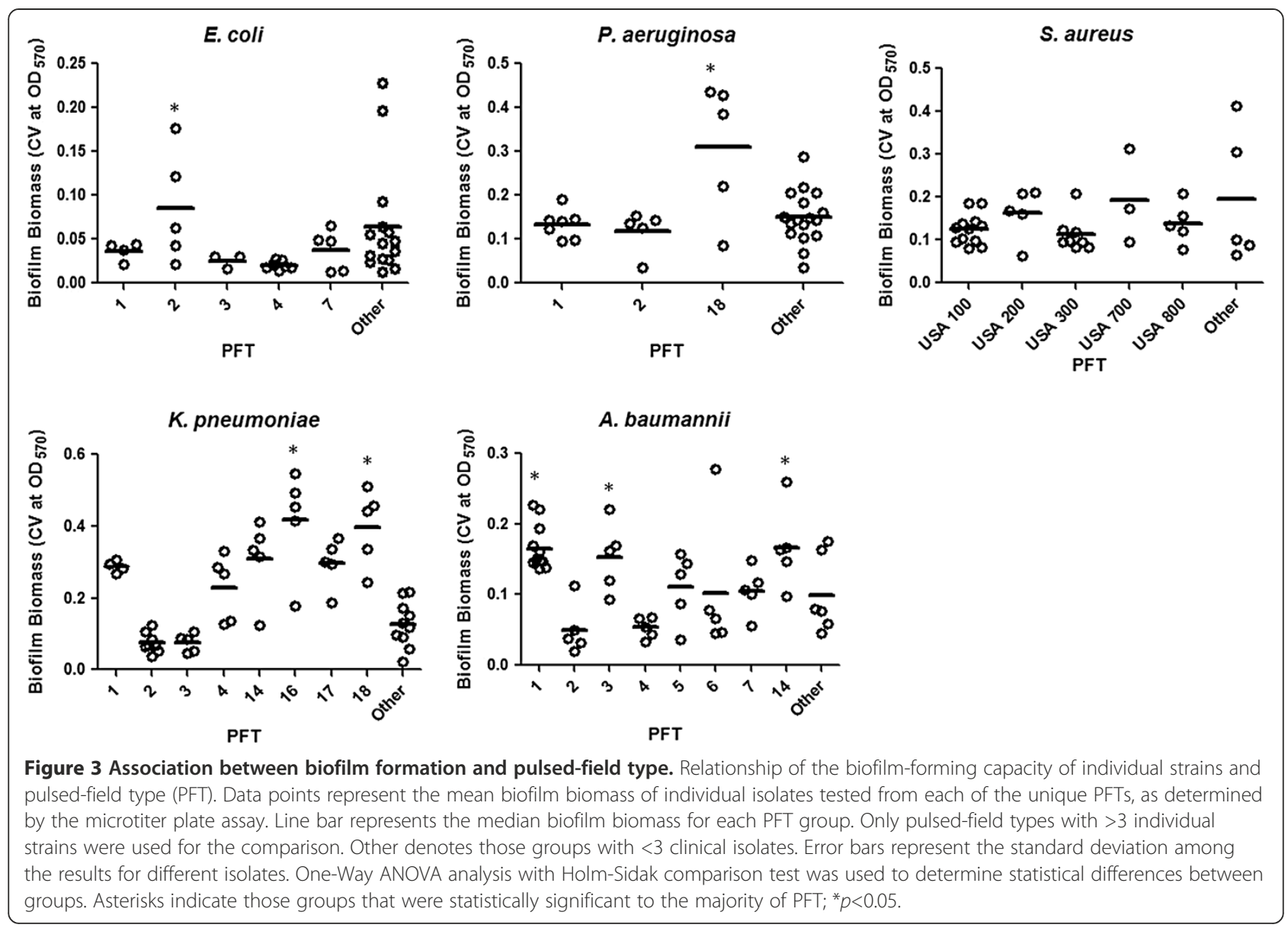

performed using the BD Phoenix ${ }^{\mathrm{TM}}$ automated microbiology system as recommended by the manufacturer (BD, Franklin Lakes, NJ). Resistance and susceptibilities to the various drugs tested are reflective of the clinical breakpoints set by the Clinical and Laboratory Standards Institute (CLSI) as described by the performance standards for antimicrobial susceptibility testing (M100-S22, Jan 2012).

\section{Pulsed-field gel electrophoresis (PFGE)}

Clonal relationships between bacterial strains of each individual species were assessed by pulsed-field gel electrophoresis (PFGE) according to the FDA method 'Procedure for PFGE of Gram-negative rods' (Version 1, 10/30/2007) and as previously described using the CHEFDRIII system (Bio-Rad Laboratories, Hercules, California) [27,28]. The endonuclease ApaI was used for A. baumannii PFGE, SmaI for MRSA PFGE, XbaI for K. pneumoniae and E. coli PFGE and SpeI was used for P. aeruginosa PFGE. Gel images were analyzed using BioNumerics software (Applied Maths, Austin, TX). PFGE patterns were interpreted and grouped into pulsed field types (PFTs) using previously established criteria [27,29].

\section{Biofilm formation in 96-well microtiter plates}

Biofilm formation was examined by the semi-quantitative determination of biofilm formation in 96-well flat bottom plates as previously described [30,31]. Briefly, fresh bacterial suspensions were prepared in either TSB or LB from overnight cultures and adjusted to $\mathrm{OD}_{600}$ of $0.1\left(\sim 10^{7}\right.$ CFU/mL). $100 \mu \mathrm{L}$ aliquots of bacterial suspension were then inoculated into individual wells of a 96-well flatbottomed polystyrene plate and incubated overnight at $37^{\circ} \mathrm{C}$ for $48 \mathrm{~h}$. Following overnight incubation, plates were gently washed with $1 \mathrm{X}$ phosphate buffered saline (PBS; pH 7.4) and stained with $100 \mu \mathrm{L}$ of $0.1 \%$ Crystal Violet (Sigma-Aldrich, St. Louis, MO) for $30 \mathrm{~min}$ at room temperature. Excess crystal violet was removed by washing, and biofilm was quantified by measuring the corresponding $\mathrm{OD}_{570 \mathrm{~nm}}$ of the supernatant following the solubilization of CV in $95 \%$ ethanol. For each clinical strain tested, biofilm assays were performed in triplicate and the mean biofilm absorbance value was determined. Strains that formed biofilms $\geq \mathrm{OD}_{570}$ of the positive control were considered to be positive for biofilm formation whereas those strains with values less than the control were considered as weak biofilm forming strains. 


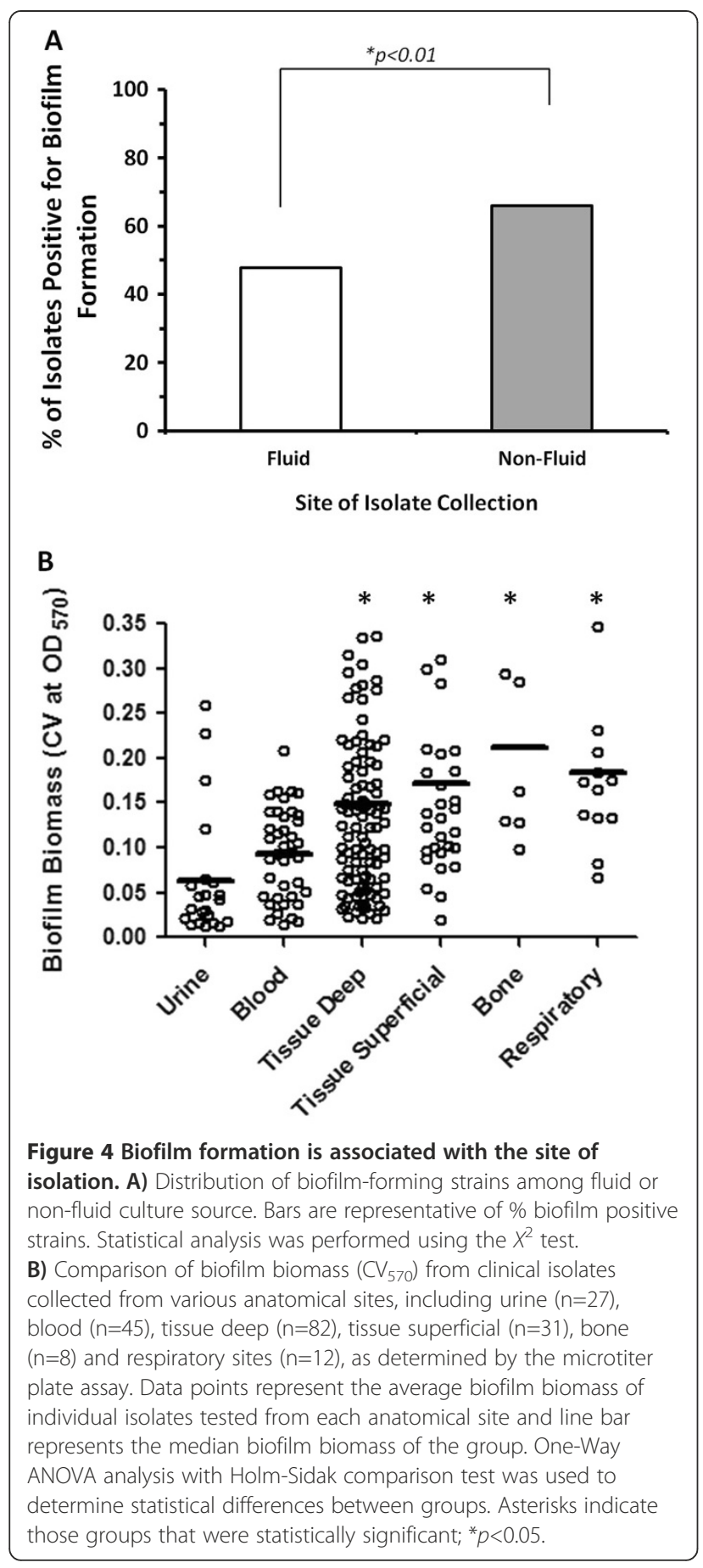

Visualization of biofilms by Scanning-Electron Microscopy (SEM)

A single representative strain from each of the individual bacterial species demonstrating significant biofilm formation based on the microtiter plate assay, were further characterized by SEM. Bacterial biofilms were grown on polystyrene pegs using the $\mathrm{MBEC}^{\mathrm{TM}}-\mathrm{P} \& \mathrm{G}$ plates (Innovotech, Alberta, Canada) for $48 \mathrm{~h}$, following the methods described above, and SEM was performed using previously described optimized conditions [32,33]. Briefly, following incubation, pegs were rinsed with $1 \mathrm{X}$ PBS and removed using sterile needle-tipped pliers. Each peg was then fixed with $2 \%(\mathrm{w} / \mathrm{v})$ glutaraldehyde, $2 \%(\mathrm{w} / \mathrm{v})$ paraformaldehyde, $0.15 \mathrm{M}$ sodium cacodylate, $0.15 \%$ $(\mathrm{w} / \mathrm{v})$ alcian blue for $3 \mathrm{hr}$ at room temperature. Pegs were then rinsed three times with $0.15 \mathrm{M}$ sodium cacodylate buffer, immersed in $1 \%(\mathrm{v} / \mathrm{v})$ osmium tetroxide in sodium cacodylate and incubated for $1 \mathrm{hr}$ at room temperature. Pegs were then rinsed three times with distilled water followed by a stepwise dehydration with ethanol (i.e. 70\%, $95 \%$, and $100 \%)$. Samples were then treated with hexamethyldisilizane for $5 \mathrm{~min}$ prior to drying in a desiccator overnight. Next day samples were sputter coated with gold palladium and viewed with a JEOL-6610 scanning electron microscope. SEM experiments were carried out in duplicate for each strain tested, and representative images of biofilms were selected.

\section{Statistical analysis}

Statistical analysis was performed using One-way ANOVA with a Holm-Sidak post-hoc evaluation for comparison between multiple groups. For non-parametric comparisons between groups, the $X^{2}$ test was performed. $P$ values of $<0.05$ were considered to be statistically significant.

\section{Results and discussion}

\section{Clinical strains have a heterogeneous capacity for biofilm} formation

The ability of clinical isolates to form biofilms is associated with the capacity of these organisms to survive within hospital environments, on implanted medical devices, and in the wounds of patients $[4,16,17]$. The majority of studies examining biofilm formation in clinical isolates to date have focused primarily on isolates representative of bacterial species associated with device related infections (Additional file 1). Consequently, limited studies on biofilm formation in certain bacterial species, including $A$. baumannii and $K$. pneumoniae, associated with other clinical diseases are available. To address this, we evaluated the ability of individual clinical isolates from a diverse collection of infecting isolates to develop biofilms using the semi-quantitative 96-well plate assay as described $[30,34,35]$. This static model of biofilm formation has been demonstrated to be a reliable and a reproducible method for assessing biofilm formation in vitro. Of the 205 clinical strains evaluated for biofilm formation, more than half of all isolates $(61.4 \% ; 126 / 205)$ were observed to be capable of forming biofilms equal to or greater than the biofilm control strain, S. epidermidis ATCC 12228 (Figure 1). As shown in Figure 1, biofilm formation by individual isolates was heterogeneous and dependent on both the bacterial species and strain. 
Table 2 Biofilm formation and antimicrobial resistance in clinical isolates

\begin{tabular}{|c|c|c|c|c|c|c|c|c|c|c|c|}
\hline \multirow{3}{*}{\multicolumn{2}{|c|}{$\% M^{a} R^{a}$}} & \multirow{2}{*}{\multicolumn{2}{|c|}{$\begin{array}{c}\text { A. baumannii } \\
\mathrm{n}=53\end{array}$}} & \multicolumn{2}{|r|}{ E. coli } & \multicolumn{2}{|c|}{ K. pneumoniae } & \multirow{2}{*}{\multicolumn{2}{|c|}{$\begin{array}{c}\text { P. aeruginosa } \\
\mathrm{n}=36\end{array}$}} & \multirow{2}{*}{\multicolumn{2}{|c|}{$\begin{array}{c}\text { S. aureus } \\
n=23\end{array}$}} \\
\hline & & & & & $\mathrm{n}=39$ & & $n=54$ & & & & \\
\hline & & \multicolumn{2}{|c|}{$86.7 \% ; 46 / 53$} & \multicolumn{2}{|r|}{$79.5 \% ; 31 / 39$} & \multicolumn{2}{|r|}{$100 \%$} & \multicolumn{2}{|c|}{$77.7 \% ; 28 / 36$} & \multicolumn{2}{|c|}{$65.2 \% ; 15 / 23$} \\
\hline \multicolumn{2}{|l|}{ Antimicrobial } & $\%^{\mathrm{b}}$ & $\begin{array}{l}\text { \%Biofilm } \\
\text { Production }\end{array}$ & $\%$ & $\%$ Biofilm Production & $\%$ & $\begin{array}{c}\% \text { Biofilm } \\
\text { Production }\end{array}$ & $\%$ & $\begin{array}{c}\% \text { Biofilm } \\
\text { Production }\end{array}$ & $\%$ & $\begin{array}{c}\% \text { Biofilm } \\
\text { Production }\end{array}$ \\
\hline \multicolumn{12}{|c|}{ Aminoglycosides } \\
\hline \multirow[t]{2}{*}{ Amikacin } & $\mathbf{R}$ & 67 & 65 & 10 & 33 & 20 & 83 & 25 & 67 & $N D$ & $N D$ \\
\hline & $S$ & 33 & 47 & 90 & 15 & 80 & 50 & 75 & 81 & $N D$ & $N D$ \\
\hline \multirow[t]{2}{*}{ Gentamicin } & $\mathbf{R}$ & 90 & 89 & 47 & 14 & 93 & 79 & 39 & 75 & 3 & 100 \\
\hline & $S$ & 10 & 67 & 53 & 19 & 7 & 71 & 61 & 59 & 97 & 90 \\
\hline \multirow[t]{2}{*}{ Tobramycin } & $\mathbf{R}$ & 70 & 81 & 53 & 19 & 53 & 81 & 23 & 90 & $N D$ & $N D$ \\
\hline & $S$ & 30 & 33 & 47 & 14 & 47 & 64 & 77 & 78 & $N D$ & $N D$ \\
\hline \multicolumn{12}{|l|}{ Ansamycins } \\
\hline \multirow[t]{2}{*}{ Rifampin } & $\mathbf{R}$ & $N D$ & $N D$ & $N D$ & $N D$ & $N D$ & $N D$ & $N D$ & $N D$ & 0 & 92 \\
\hline & $S$ & $N D$ & $N D$ & $N D$ & $N D$ & $N D$ & $N D$ & $N D$ & $N D$ & 100 & 78 \\
\hline \multicolumn{12}{|l|}{ Cephalosporins } \\
\hline \multirow[t]{2}{*}{ Cefazolin } & $\mathbf{R}$ & $N D$ & $N D$ & 93 & 14 & 90 & 67 & 100 & 80 & 69 & 99 \\
\hline & $S$ & $N D$ & $N D$ & 7 & 50 & 10 & 0 & 0 & 0 & 31 & 50 \\
\hline Cefepime & $\mathbf{R}$ & $N D$ & $N D$ & 77 & 9 & 93 & 82 & 63 & 79 & $N D$ & $N D$ \\
\hline & $S$ & $N D$ & $N D$ & 23 & 43 & 7 & 56 & 37 & 82 & $N D$ & $N D$ \\
\hline Cefoxitin & $\mathbf{R}$ & $N D$ & $N D$ & 10 & 67 & 13 & 100 & 100 & 80 & 74 & 95 \\
\hline & $S$ & $N D$ & $N D$ & 90 & 11 & 87 & 65 & 0 & 0 & 26 & 60 \\
\hline Cefotaxime & $\mathbf{R}$ & 80 & 63 & $N D$ & $N D$ & 93 & 68 & $N D$ & $N D$ & $N D$ & $N D$ \\
\hline & $\mathbf{S}$ & 20 & 50 & $N D$ & $N D$ & 7 & 100 & $N D$ & $N D$ & $N D$ & $N D$ \\
\hline Ceftazidime & $\mathbf{R}$ & 53 & 44 & 77 & 13 & 97 & 86 & 67 & 90 & $N D$ & $N D$ \\
\hline & $S$ & 47 & 93 & 23 & 29 & 3 & 33 & 33 & 60 & $N D$ & $N D$ \\
\hline Ceftriaxone & $\mathbf{R}$ & $N D$ & $N D$ & 80 & 13 & 87 & 73 & 100 & 80 & $N D$ & $N D$ \\
\hline & $S$ & $N D$ & $N D$ & 20 & 33 & 13 & 69 & 0 & 0 & $N D$ & $N D$ \\
\hline Carbepenems & & & & & & & & & & & \\
\hline Imipenem & $\mathbf{R}$ & 67 & 85 & 0 & 0 & 0 & 0 & 75 & 86 & $N D$ & $N D$ \\
\hline & $S$ & 33 & 30 & 100 & 17 & 100 & 70 & 25 & 95 & $N D$ & $N D$ \\
\hline Meropenem & $\mathbf{R}$ & 67 & 85 & 0 & 0 & 0 & 0 & 58 & 78 & $N D$ & $N D$ \\
\hline & $S$ & 33 & 30 & 100 & 17 & 100 & 70 & 42 & 82 & $N D$ & $N D$ \\
\hline Flouroquinolones & & & & & & & & & & & \\
\hline Ciprofloxacin & $\mathbf{R}$ & 90 & 85 & 83 & 12 & 63 & 79 & 75 & 80 & $N D$ & $N D$ \\
\hline & $S$ & 10 & 33 & 17 & 40 & 37 & 45 & 25 & 100 & $N D$ & $N D$ \\
\hline Levofloxacin & $\mathbf{R}$ & 57 & 71 & 83 & 12 & 50 & 80 & 80 & 92 & 50 & 93 \\
\hline & $S$ & 43 & 92 & 17 & 40 & 50 & 60 & 20 & 50 & 50 & 80 \\
\hline Penicillins & & & & & & & & & & & \\
\hline Ampicillin & $\mathbf{R}$ & 100 & 67 & 97 & 17 & 100 & 70 & 100 & 80 & 100 & 100 \\
\hline & $S$ & 0 & 0 & 3 & 0 & 0 & 0 & 0 & 0 & 0 & 0 \\
\hline Aztreonam & $\mathbf{R}$ & 100 & 67 & 73 & 9 & 97 & 90 & 73 & 73 & $N D$ & $N D$ \\
\hline & $S$ & 0 & 0 & 27 & 38 & 3 & 100 & 27 & 100 & $N D$ & $N D$ \\
\hline Oxacillin & $\mathbf{R}$ & $N D$ & $N D$ & $N D$ & $N D$ & $N D$ & $N D$ & $N D$ & $N D$ & 83 & 92 \\
\hline & $S$ & $N D$ & $N D$ & $N D$ & $N D$ & $N D$ & $N D$ & $N D$ & $N D$ & 17 & 60 \\
\hline Piperacillin & $\mathbf{R}$ & 93 & 71 & 13 & 0 & 30 & 78 & 67 & 75 & $N D$ & $N D$ \\
\hline & $S$ & 7 & 100 & 87 & 19 & 60 & 61 & 33 & 90 & $N D$ & $N D$ \\
\hline
\end{tabular}


Table 2 Biofilm formation and antimicrobial resistance in clinical isolates (Continued)

\begin{tabular}{cccccccccccc}
\hline Tetracyclines & & & & & & & & & \\
Tetracycline & R & 80 & 71 & 67 & 20 & 63 & 58 & ND & ND & 20 & 83 \\
& S & 20 & 50 & 33 & 10 & 37 & 91 & ND & ND & 80 & 88 \\
Sulfonamides & & & & & & & & & \\
Trimeth-Sulfameth & R & 90 & 78 & 77 & 17 & 73 & 86 & 100 & 80 & 0 \\
& S & 10 & 50 & 23 & 14 & 27 & 50 & 0 & 0 & 1000 & 87 \\
\hline
\end{tabular}

${ }^{a}$ A multidrug-resistant (MDR) organism was defined as any extented spectrum-lactamase (ESBL) producing bacteria, or if resistant to all tested antimicrobials on 3 or more classes of antimicrobial agent.

${ }^{b} \%$; indicates the percentage of isolates resistant $(\mathrm{R})$ or sensitive $(\mathrm{S})$ to each antimicrobial agent. Antimicrobial suceptibilities were determined using BD Phoenix ${ }^{\mathrm{T} M}$ automated microbiology system and are reflective of clinical breakpoints.

Of the $23 \mathrm{~S}$. aureus isolates tested, 21 strains (91\%) were positive for biofilm formation, with a median biofilm biomass of $0.121 \pm 0.074$ and $0.161 \pm 0.072$ for MRSA and MSSA, respectively. Consistent with previous reports, no significant differences in biofilm formation between the MRSA and MSSA strains were observed $(p=0.40)$, indicating no significant correlation between methicillin susceptibility and the ability to form biofilms [21,22]. In $K$. pneumoniae, 41 of the 54 isolates tested (76\%) were determined to be positive for biofilm formation with a median biofilm biomass of $0.214 \pm 0.118$. Likewise, in $P$. aeruginosa and A. baumannii, 30 of 36 (83\%) and 29 of 53 (55\%) of clinical strains tested were observed to form biofilms with a median biofilm biomass of $0.142 \pm 0.094$ and $0.125 \pm 0.061$, respectively. In contrast, $E$. coli was the weakest biofilm forming group with only 5 of the 39 strains (13\%) capable of forming biofilms greater than the control strain and having the lowest biofilm biomass (median 0.044 \pm 0.018 ). As the majority of $E$. coli strains (64.2\%) were collected from fluid sites, blood (10.2\%; 1 biofilm positive) and urine (54\%; 3 biofilm positive), and those strains positive for biofilm formation were primarily from these sites, the low prevalence of biofilm formation observed herein is likely the result of the random sampling from our collection as well as the strain types represented, discussed below, as previous studies have demonstrated that clinical isolates of E. coli are capable of forming biofilms in vitro [23]. Importantly for those strains that were observed to be poor biofilm formers in vitro, these strains may still be important during polymicrobial infections where they can directly be incorporated into an established biofilm or interact with other species providing synergy to the biofilm formers.

As confirmation of biofilm formation using the 96 well plate model, we examined biofilm formation by scanning electron microscopy (SEM) using the $\mathrm{MBEC}^{\mathrm{TM}}-\mathrm{P} \& \mathrm{G}$ plates as previously described [32,33]. For this study, single representative isolates from each species positive for biofilm formation, as determined by the microtiter plate method, were selected for SEM analysis. In agreement with the results from the microtiter plate assay, SEM studies demonstrated that the strains selected were capable of forming mature, robust biofilms on the peg surface, albeit the mature biofilm structures and phenotypes observed were unique for each species (Figure 2A-G). Together these findings demonstrate that biofilm formation is a prevalent feature amongst clinical strains associated with numerous infectious syndromes.

\section{Relationship of biofilm formation to pulsed-field type and culture site}

The 205 isolates tested for biofilm formation herein represented $>29$ unique PFTs in the five different bacterial species, which were representative of the range of clinical strains encountered within our healthcare treatment facility. The pathogenic potential of numerous organisms has been linked to the PFT. For example, MRSA USA300 has been implicated in outbreaks within the US, accounting for up to $70 \%$ of all skin and soft tissue infections [36,37]. Given the relationship between PFT and strain virulence, we evaluated whether a similar association between biofilm formation and PFT could be made.

Indeed, for each of the bacterial species evaluated there was a significant association between specific PFT groups and biofilm formation (Figure 3). In E. coli and $P$. aeruginosa, clinical isolates belonging to PFT-2 $(\mathrm{n}=5)$ $(p<0.001)$ and PFT-18 $(\mathrm{n}=5) \quad(p<0.001)$ groups respectively, had a significantly greater ability to form biofilms, as determined by crystal violet staining of biofilms, compared to those strains within the other PFT groups. In S. aureus, strains belonging to USA200 and USA 300 had a moderate, albeit insignificant, increased ability to form biofilms compared to the other PFT. In contrast, multiple PFTs in $K$. pneumoniae, including PFT-1 $(\mathrm{n}=6)$, $4,14,16,17$, and $18(n=5)$, were associated with high biofilm formation of which PFT-16 $(\mathrm{n}=5)(p<0.01)$ and PFT-18 $(n=5)(p<0.01)$ isolates were associated with the greatest ability to form biofilms. In contrast, those isolates belonging to PFTs $2(n=8)$ and $3(n=5)$ were weak 
Table 3 Biofilm formation of serial isolates recovered from patients with clinical relapse involving clones identical to the initial isolate

\begin{tabular}{|c|c|c|c|c|c|c|}
\hline Patient & Bacterium & Isolate & Source & Days after initial isolate & $\mathrm{PFT}^{a}$ & Biofilm former $^{b}$ \\
\hline \multirow[t]{6}{*}{1} & A. baumannii & 1 & Deep tissue & 0 & 1 & Yes \\
\hline & & 2 & Deep tissue & 3 & 1 & Yes \\
\hline & & 3 & Bone & 8 & 1 & Yes \\
\hline & & 4 & Deep tissue & 68 & 1 & Yes \\
\hline & & 5 & Deep tissue & 70 & 1 & Yes \\
\hline & & 6 & Deep tissue & 127 & 1 & Yes \\
\hline \multirow[t]{12}{*}{2} & P. aeruginosa & 1 & Blood & 0 & 1 & Yes \\
\hline & & 2 & Blood & 1 & 1 & Yes \\
\hline & & 3 & Blood & 17 & 1 & Yes \\
\hline & & 4 & Deep tissue & 21 & 1 & Yes \\
\hline & & 5 & Pleural fluid & 25 & 1 & No \\
\hline & & 6 & Deep tissue & 29 & 1 & Yes \\
\hline & & 7 & Blood & 36 & 1 & Yes \\
\hline & & 8 & Deep tissue & 42 & 1 & Yes \\
\hline & & 9 & Respiratory tract & 43 & 1 & Yes \\
\hline & & 10 & Blood & 46 & 1 & No \\
\hline & & 11 & Respiratory tract & 49 & 1 & Yes \\
\hline & & 12 & Blood & 51 & 1 & Yes \\
\hline \multirow[t]{5}{*}{3} & P. aeruginosa & 1 & Groin swab & 0 & A & Yes \\
\hline & & 2 & Superficial tissue & 332 & B & No \\
\hline & & 3 & Superficial tissue & 332 & B & Yes \\
\hline & & 4 & Deep tissue & 522 & A & Yes \\
\hline & & 5 & Deep tissue & 522 & A & Yes \\
\hline \multirow[t]{2}{*}{4} & P. aeruginosa & 1 & Deep tissue & 0 & 19 & Yes \\
\hline & & 2 & Deep tissue & 158 & 19 & Yes \\
\hline \multirow[t]{9}{*}{5} & $M R S A^{c}$ & 1 & Deep abscess & 0 & USA300 & Yes \\
\hline & & 2 & Deep abscess & 0 & USA300 & Yes \\
\hline & & 3 & Superficial abscess & 16 & USA300 & Yes \\
\hline & & 4 & Nares swab & 105 & USA300 & Yes \\
\hline & & 5 & Nares swab & 161 & USA300 & Yes \\
\hline & & 6 & Nares swab & 202 & USA300 & Yes \\
\hline & & 7 & Superficial fluid & 224 & USA300 & Yes \\
\hline & & 8 & Superficial tissue & 247 & USA300 & Yes \\
\hline & & 9 & Deep tissue & 248 & USA300 & Yes \\
\hline
\end{tabular}

a Pulsed-field type (PFT).

${ }^{b}$ Strains with Crystal Violet absorbance greater than or equal to that of Staphylococcus epidermidis ATCC 12228 (positive control) were considered to be positive for biofilm formation.

c Methicillin-resistant S. aureus.

biofilm forming strains. With the exception of PFTs-2 and $4(\mathrm{n}=5)$, the majority of the PFTs for A. baumannii were also associated with biofilm formation of which isolates from PFT-1 $(\mathrm{n}=13), 3$, and $14 \quad(\mathrm{n}=5) \quad(p<0.05)$ groups were associated with a greater ability to form biofilms. With the exception of a few studies evaluating the relationship of biofilm formation to SSCmec and spa typing in S. aureus, our study is the first to characterize and identify PFT groups associated with biofilm formation for K. pneumoniae, $P$. aeruginosa, and $A$. baumannii.

In addition to PFT, a strong correlation between biofilm formation and the site of isolate collection was observed. 
Clinical strains isolated from non-fluid sites including superficial/deep tissue, bone, and respiratory tract on average had a significantly higher proportion of biofilm positive strains compared to those isolates from host fluids, including blood or urine $(p=0.01)$ (Figure 4A). Consistent with this, comparison of biofilm averages amongst clinical strains grouped into individual collection sites, demonstrated that isolates from superficial/deep tissue, bone, and respiratory tract (i.e. non-fluid culture sites) on average displayed enhanced biofilm formation, as determined by $\mathrm{CV}$ measurement, compared to those isolates from blood and urine $(p<0.01)$ (Figure 4B). This may reflect adaptations favoring the survival of organisms in non-liquid physiologic environments, which may explain in part the difficulty in eradicating some infections once they become established in solid tissues. Of note, isolates from bone, including S. aureus and K. pneumoniae, had a significantly greater ability to form biofilms compared to the isolates collected from respiratory, superficial, and deep tissue groups ( $p=0.04, p=0.02$ and $p<0.001$ respectively).

Together these findings implicate that at various anatomical sites, such as bone and soft tissue, biofilm formation may play a role in the successful colonization and/ or the subsequent development of invasive disease at these particular wound sites which is partly dependent on PFT.

\section{Biofilm formation and multidrug-resistance}

Antimicrobial resistance is an innate feature of bacterial biofilms that, in addition to the increasing rates of reported antimicrobial resistance amongst clinical strains, may further complicate patient treatment $[21,38]$. In comparing antimicrobial resistance to the ability of biofilm formation in the individual strains, we observed that strains capable of forming biofilms were more frequently observed to be an MDR phenotype (Table 2). In A. baumannii, strains capable of forming biofilms were more often observed to be resistant to aminoglycosides, carbepenems, tetracyclines, and sulfonamides compared to those strains characterized as weak biofilm producers. Similarly in $K$. pneumoniae and $S$. aureus, the ability to form biofilms was observed in strains to be resistant to cephalosporins and fluoroquinolones, respectively. Likewise, in $P$. aeruginosa strains positive for biofilm formation more commonly demonstrated a resistance phenotype to cephalosporins. Because the majority of isolates selected to evaluate biofilm formation were predominately MDR organisms, the interpretations of these results are limited. However, as previous studies have shown that biofilm formation is higher in MDR strains [20,21,39], and can promote antimicrobial resistance by selecting for highly resistant strains following treatment with sub-inhibitory antimicrobial concentrations [40,41], the ability of a strain to develop biofilms may have an important, yet not fully understood role in the development of multidrug resistance.

\section{Biofilm formation among isolates from persistent infections}

As biofilm formation has been shown to be a mechanism for evading host-defenses and resisting the effect of antimicrobials, it has been suggested that strains capable of forming biofilms may persist within the host contributing to relapsing/chronic infections $[4,5,42]$. Despite our understanding of biofilms, few studies have provided evidence directly implicating this phenotype in persistent infections. To examine the relationship between biofilm formation and relapsing infection, we assessed whether serial isolates from five patients with persistent infections were more likely to be positive for biofilm formation. In all five of the patients, the duration between the first and last isolate collection ranged from 0 to $>100$ days (Table 3 ). In patients 2,3 , and 5 a number of the serial isolates evaluated were collected from various sterile anatomical sites unique to site of the first isolate. With the exception of 3 of the isolates $(3 / 34 ; 9 \%)$, the majority of serial isolates $(31 / 34 ; 91 \%)$ from the five patients were positive for biofilm formation and was consistent between the sequential isolates even those with recovery times $>100$ days apart, as determined by measurement of biofilm by $\mathrm{CV}$. The frequency of biofilm positive strains isolated from patients with relapsing infections is interesting and indicates a potential role for biofilm formation in these types of infection; however, future studies evaluating larger patient populations with relapsing infections and evaluating additional clinical outcomes would be necessary to fully evaluate the relationship between these two properties.

\section{Conclusions}

We found a high prevalence of biofilm-forming phenotypes among a large number of clinical isolates representing a diversity of species, genotypes and anatomic culture sites of origin. In addition, biofilm formation was prevalent among isolates with a MDR phenotype. To our knowledge, this study is the first to demonstrate biofilm formation by serial isolates recovered from relapsing clinical infections including molecular characterizations of strain relatedness, and contributes to a limited number of studies examining biofilm formation by Gram-negative bacilli beyond the context of urinary tract infections. Our findings highlight the importance of the bacterial biofilm phenotype as a potential virulence factor which may contribute to the clinical relapse of infections.

\section{Additional file}

Additional file 1: Literature search of previous studies evaluating biofilm formation by clinical isolates in vitro. List of previous studies comparing biofilm formation by clinical isolates in various bacterial species, emphasizing the focus of study, strains and methods used to quantify biofilm formation, and conclusions drawn from studies. 


\section{Competing interests}

The authors declare that they have no competing interests.

\section{Authors' contributions}

CJS participated in the study design, experimental study and data analysis, and wrote the final draft of this manuscript. KM, MLB, and DRR performed the experimental study and acquisition of data. KM, KSA, JCW, and CKM participated in the study design, data analysis, and helped review the manuscript. All authors read and approved the final manuscript.

\section{Acknowledgments}

This work was supported by intramural funding from the Combat Casualty Research Program, Medical Research and Materiel Command to JCW, and Armed Forces Health Surveillance Center including the Global Emerging Infectious System to CKM. CJS is supported by a Post-doctoral Research Associate Fellowship through the National Academy of Sciences. KM is supported through the USUHS Infectious Disease Clinical Research Program. The authors would like to thank Ms. Barbara Hunter at the University of Texas Health Science Center (UTHSCSA) Institutional Electron Microscopy core facility for her assistance with the preparation and processing of samples for scanning electron microscopy. Disclaimer: The views expressed herein are those of the authors and do not reflect the official policy or position of the Department of the Army, Department of Defense, or the US Government. The authors are employees of the US government. This work was prepared as part of their official duties and, as such, there is no copyright to be transferred.

\section{Author details}

${ }^{1}$ Department of Extremity Trauma and Regenerative Medicine, United States Army Institute of Surgical Research, Ft. Sam Houston, San Antonio, TX, USA. ${ }^{2}$ Infectious Disease Clinical Research Program, Uniformed Services University of the Health Sciences, Bethesda, MD, USA. ${ }^{3}$ Department of Medicine, Infectious Disease Service, San Antonio Military Medical Center, Ft. Sam Houston, San Antonio, TX, USA. ${ }^{4}$ Department of Clinical Investigation, San Antonio Military, Medical Center, Ft. Sam Houston, San Antonio, TX, USA.

Received: 21 August 2012 Accepted: 23 January 2013

Published: 29 January 2013

\section{References}

1. Bergogne-Berezin E, Decre D, Joly-Guillou ML: Opportunistic nosocomial multiply resistant bacterial infections--their treatment and prevention. J Antimicrob Chemother 1993, 32(Suppl A):39-47.

2. McGrath EJ, Asmar BI: Nosocomial infections and multidrug-resistant bacterial organisms in the pediatric intensive care unit. Indian J Pediatr 2011, 78:176-184.

3. Edwards R, Harding KG: Bacteria and wound healing. Curr Opin Infect Dis 2004, 17:91-96.

4. Hall-Stoodley L, Costerton JW, Stoodley P: Bacterial biofilms: from the natural environment to infectious diseases. Nat Rev Microbiol 2004, 2:95-108.

5. Percival SL: Biofilms and their potential role in wound healing. Wounds 2004, 16:234-240.

6. Costerton JW: Introduction to biofilm. Int J Antimicrob Agents 1999, 11:217-221. discussion 237-219.

7. Dotsch A, Eckweiler D, Schniederjans M, Zimmermann A, Jensen V, Scharfe $M$, Geffers R, Haussler S: The pseudomonas aeruginosa transcriptome in planktonic cultures and static biofilms using RNA sequencing. PLOS One 2012, 7:e31092.

8. Sauer K, Camper AK, Ehrlich GD, Costerton JW, Davies DG: Pseudomonas aeruginosa displays multiple phenotypes during development as a biofilm. J Bacterio/ 2002, 184:1140-1154.

9. Anderson GG, O'Toole GA: Innate and induced resistance mechanisms of bacterial biofilms. Curr Top Microbiol Immunol 2008, 322:85-105.

10. Mah TF, O'Toole GA: Mechanisms of biofilm resistance to antimicrobial agents. Trends Microbiol 2001, 9:34-39.

11. Schommer NN, Christner M, Hentschke M, Ruckdeschel K, Aepfelbacher M, Rohde $\mathrm{H}$ : Staphylococcus epidermidis uses distinct mechanisms of biofilm formation to interfere with phagocytosis and activation of mouse macrophage-like cells 774A.1. Infect Immun 2011, 79:2267-2276.

12. Thurlow LR, Hanke ML, Fritz T, Angle A, Aldrich A, Williams SH, Engebretsen IL, Bayles KW, Horswill AR, Kielian T: Staphylococcus aureus biofilms prevent macrophage phagocytosis and attenuate inflammation in vivo. J Immunol 2011, 186:6585-6596.

13. Davis SC, Ricotti C, Cazzaniga A, Welsh E, Eaglstein WH, Mertz PM: Microscopic and physiologic evidence for biofilm-associated wound colonization in vivo. Wound Repair Regen 2008, 16:23-29.

14. Dowd SE, Wolcott RD, Sun Y, McKeehan T, Smith E, Rhoads D: Polymicrobial nature of chronic diabetic foot ulcer biofilm infections determined using bacterial tag encoded FLX amplicon pyrosequencing (bTEFAP). PLoS One 2008, 3:e3326.

15. James GA, Swogger E, Wolcott R, Pulcini E, Secor P, Sestrich J, Costerton JW, Stewart PS: Biofilms in chronic wounds. Wound Repair Regen 2008, 16:37-44.

16. Costerton JW, Stewart PS, Greenberg EP: Bacterial biofilms: a common cause of persistent infections. Science 1999, 284:1318-1322.

17. Donlan RM, Costerton JW: Biofilms: survival mechanisms of clinically relevant microorganisms. Clin Microbiol Rev 2002, 15:167-193.

18. Garza-Gonzalez E, Morfin-Otero R, Martinez-Vazquez MA, Gonzalez-Diaz E, Gonzalez-Santiago O, Rodriguez-Noriega E: Microbiological and molecular characterization of human clinical isolates of Staphylococcus cohnii, Staphylococcus hominis, and Staphylococcus sciuri. Scand J Infect Dis 2011, 43:930-936.

19. Kawamura H, Nishi J, Imuta N, Tokuda K, Miyanohara H, Hashiguchi T, Zenmyo M, Yamamoto T, ljiri K, Kawano Y, Komiya S: Quantitative analysis of biofilm formation of methicillin-resistant Staphylococcus aureus (MRSA) strains from patients with orthopaedic device-related infections. FEMS Immunol Med Microbiol 2011, 63:10-15.

20. Kwon AS, Park GC, Ryu SY, Lim DH, Lim DY, Choi CH, Park Y, Lim Y: Higher biofilm formation in multidrug-resistant clinical isolates of Staphylococcus aureus. Int J Antimicrob Agents 2008, 32:68-72.

21. Reiter KC TGDASP, CF DEO, D'Azevedo PA: High biofilm production by invasive multiresistant staphylococci. APMIS 2011, 119:776-781.

22. Smith K, Perez A, Ramage G, Lappin D, Gemmell CG, Lang S: Biofilm formation by Scottish clinical isolates of Staphylococcus aureus. J Med Microbiol 2008, 57:1018-1023.

23. Cremet L, Corvec S, Bemer P, Bret L, Lebrun C, Lesimple B, Miegeville AF, Reynaud A, Lepelletier D, Caroff N: Orthopaedic-implant infections by Escherichia coli: molecular and phenotypic analysis of the causative strains. J Infect 2012, 64:169-175.

24. Revdiwala S, Rajdev BM, Mulla S: Characterization of bacterial etiologic agents of biofilm formation in medical devices in critical care setup. Crit Care Res Pract 2012, 2012:945805.

25. Pettit RK, Weber CA, Kean MJ, Hoffmann H, Pettit GR, Tan R, Franks KS, Horton ML: Microplate Alamar blue assay for Staphylococcus epidermidis biofilm susceptibility testing. Antimicrob Agents Chemother 2005, 49:2612-2617.

26. Wang X, Qiu S, Yao X, Tang T, Dai K, Zhu Z: Berberine inhibits Staphylococcus epidermidis adhesion and biofilm formation on the surface of titanium alloy. J Orthop Res 2009, 27:1487-1492.

27. Akers KS, Mende K, Yun HC, Hospenthal DR, Beckius ML, Yu X, Murray CK: Tetracycline susceptibility testing and resistance genes in isolates of Acinetobacter baumannii-Acinetobacter calcoaceticus complex from a U. S. military hospital. Antimicrob Agents Chemother 2009, 53:2693-2695.

28. McDougal LK, Steward CD, Killgore GE, Chaitram JM, McAllister SK, Tenover FC: Pulsed-field gel electrophoresis typing of oxacillin-resistant Staphylococcus aureus isolates from the United States: establishing a national database. J Clin Microbiol 2003, 41:5113-5120.

29. Tenover FC, Arbeit RD, Goering RV, Mickelsen PA, Murray BE, Persing DH, Swaminathan B: Interpreting chromosomal DNA restriction patterns produced by pulsed-field gel electrophoresis: criteria for bacterial strain typing. J Clin Microbiol 1995, 33:2233-2239.

30. Cassat JE, Lee CY, Smeltzer MS: Investigation of biofilm formation in clinical isolates of Staphylococcus aureus. Methods Mol Biol 2007, 391:127-144.

31. Christensen GD, Simpson WA, Younger JJ, Baddour LM, Barrett FF, Melton DM, Beachey EH: Adherence of coagulase-negative staphylococci to plastic tissue culture plates: a quantitative model for the adherence of staphylococci to medical devices. J Clin Microbiol 1985, 22:996-1006.

32. Ceri H, Olson ME, Stremick C, Read RR, Morck D, Buret A: The Calgary Biofilm Device: new technology for rapid determination of antibiotic susceptibilities of bacterial biofilms. J Clin Microbio/ 1999, 37:1771-1776.

33. Coraca-Huber DC, Fille M, Hausdorfer J, Pfaller K, Nogler M: Evaluation of MBEC-HTP biofilm model for studies of implant associated infections. J Orthop Res 2012, 30:1176-1180. 
34. Knezevic P, Petrovic O: A colorimetric microtiter plate method for assessment of phage effect on Pseudomonas aeruginosa biofilm. J Microbiol Methods 2008, 74:114-118.

35. Merritt JH, Kadouri DE, OToole GA: Growing and analyzing static biofilms. Curr Protoc Microbiol 2005, Chapter 1:Unit 1B 1.

36. Church D, Elsayed S, Reid O, Winston B, Lindsay R: Burn wound infections. Clin Microbiol Rev 2006, 19:403-434.

37. Mine Y, Higuchi W, Taira K, Nakasone I, Tateyama M, Yamamoto T, Uezato H, Takahashi K: Nosocomial outbreak of multidrug-resistant USA300 methicillin-resistant Staphylococcus aureus causing severe furuncles and carbuncles in Japan. J Dermatol 2011, 38:1167-1171.

38. Rajamohan G, Srinivasan VB, Gebreyes WA: Biocide-tolerant multidrugresistant Acinetobacter baumannii clinical strains are associated with higher biofilm formation. J Hosp Infect 2009, 73:287-289.

39. Rao RS, Karthika RU, Singh SP, Shashikala P, Kanungo R, Jayachandran S, Prashanth K: Correlation between biofilm production and multiple drug resistance in imipenem resistant clinical isolates of Acinetobacter baumannii. Indian J Med Microbiol 2008, 26:333-337.

40. Rachid S, Ohlsen K, Witte W, Hacker J, Ziebuhr W: Effect of subinhibitory antibiotic concentrations on polysaccharide intercellular adhesin expression in biofilm-forming Staphylococcus epidermidis. Antimicrob Agents Chemother 2000, 44:3357-3363.

41. Wang Q, Sun FJ, Liu Y, Xiong LR, Xie LL, Xia PY: Enhancement of biofilm formation by subinhibitory concentrations of macrolides in icaADBCpositive and -negative clinical isolates of Staphylococcus epidermidis. Antimicrob Agents Chemother 2010, 54:2707-2711.

42. Bjarnsholt T, Kirketerp-Moller K, Jensen PO, Madsen KG, Phipps R, Krogfelt K, Hoiby N, Givskov M: Why chronic wounds will not heal: a novel hypothesis. Wound Repair Regen 2008, 16:2-10.

doi:10.1186/1471-2334-13-47

Cite this article as: Sanchez et al:: Biofilm formation by clinical isolates and the implications in chronic infections. BMC Infectious Diseases 2013 13:47.

\section{Submit your next manuscript to BioMed Central and take full advantage of:}

- Convenient online submission

- Thorough peer review

- No space constraints or color figure charges

- Immediate publication on acceptance

- Inclusion in PubMed, CAS, Scopus and Google Scholar

- Research which is freely available for redistribution 